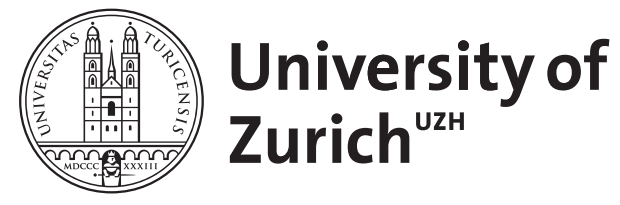

A new measure for party coherence: applying a physics-based concept to the swiss party system

Christen, Markus ; Ott, Thomas ; Schwarz, D

DOI: https://doi.org/10.1142/S0219525913500112

Posted at the Zurich Open Repository and Archive, University of Zurich ZORA URL: https://doi.org/10.5167/uzh-81458

Journal Article

Accepted Version

Originally published at:

Christen, Markus; Ott, Thomas; Schwarz, D (2013). A new measure for party coherence: applying a physics-based concept to the swiss party system. Advances in Complex Systems:1350011.

DOI: https://doi.org/10.1142/S0219525913500112 


\title{
NEW MEASURE FOR PARTY COHERENCE: APPLYING A PHYSICS-BASED CONCEPT TO THE SWISS PARTY SYSTEM
}

\author{
MARKUS CHRISTEN \\ Institute of Biomedical Ethics, University of Zurich \\ Pestalozzistrasse 24, CH-8032 Zurich, Switzerland \\ christen@ethik.uzh.ch \\ THOMAS OTT \\ Institute of Applied Simulation, Zurich University of Applied Sciences \\ Einsiedlerstrasse 31a, CH-8820 Wädenswil, Switzerland \\ thomas.ott@zhaw.ch \\ DANIEL SCHWARZ \\ Department of Methodology, London School of Economics \\ Houghton Street, London WC2A 2AE, United Kingdom \\ daniel.schwarz@politools.net \\ Received (15.02.2012) \\ Revised (17.09.2012) \\ Accepted (Day Month Year)
}

\begin{abstract}
The article revives a theoretical definition of party coherence as being composed of two basic elements, cohesion and factionalism, to propose and apply a novel empirical measure based on spin physics. The simultaneous analysis of both components using a single measurement concept is applied to data representing the political beliefs of candidates in the Swiss general elections of 2003 and 2007, proposing a connection between the coherence of the beliefs party members hold and the assessment of parties being at risk of splitting. We also compare our measure with established polarization measures and demonstrate its advantage with respect to multidimensional data that lack clear structure. Furthermore, we outline how our analysis supports the distinction between bottom-up and top-down mechanisms of party splitting. In this way, we are able to turn the intuition of coherence into a defined quantitative concept that, additionally, offers a methodological basis for comparative research of party coherence. Our work serves as an example of how a complex systems approach allows to get a new perspective on a long-standing issue in political science.
\end{abstract}

Keywords: Measurement Methods; Party Coherence; Polarization; Political Science; Superparamagnetic Clustering

\section{Introduction: Toward a New Intuition of Party Coherence}

Parties are non-unitary entities $[15,35,41,42]$. They only "behave 'as if' they were unitary actors when they have to, in situations where undisciplined behavior will 
impose high collective costs" ([47]: p. 281). However, aside from such 'imperative' moments, daily intra-party politics involves internal struggles over policies, strategies, or offices [15, 40, 43]. Thus, the emergence of factions, wings, and sub-groups is a fact of life in most party organizations [28, 24], as it is a manifestation of internal diversity [19]. Party organizations constitute "collections of individuals or coalitions of sub-party groups with common but also divergent preferences and interests and with competing claims on party resources" ([5]: p. 56) rather than monolithic units. Thus, parties differ with respect to party coherence, which Janda defined as the "degree of congruence in the attitudes and behavior of party members" ([33]: p. 118) and involves two elements: cohesion and factionalism [34].

Understanding the kind and degree of coherence within a party organization is important for comparing political parties and characterizing the dynamics of party change, which itself contributes to political change within a society. In this paper, we provide a new coherence measure in order to capture important dimensions of party structure using one single measurement concept. Our concept does not involve a new model for party dynamics; rather, it provides a tool to describe party coherence based, e.g., on survey data of beliefs party members hold on political issues. As we outline in section 2, our measure has a broad spectrum of applications; the current contribution provides an example of how a complex systems approach allows getting a new perspective on long-standing issues in social sciences.

We consider party politics and, in particular, the Swiss party system a fruitful topic for applying our measure of coherence due to three reasons: First, although considerable theoretical work on party dynamics has been published (e.g. [23]) and recent research has shown novel insights with respect to diversity within parties, the literature is underdeveloped in terms of quantitative efforts. Second, while various measures for capturing the organizational structure of parties exist, they usually grasp only one dimension of this complex phenomenon. Third, Switzerland recently experienced two party splits and one party merger in the last decade that makes this country an ideal test-case for our measure.

With respect to the first motivation for our paper, an interesting change in the literature on party dynamics is observable. Contrary to the prevalent view that internally fragmented parties are alien to the parliamentary regime type because they send mixed signals to their voters about the policies they pursue, prove to be less effective in parliament, and are doubtful partners in government coalitions [7, $8,40,42]$, recent research has shown that factions take up different and positive functions for parties. This, however, depends on the "kind" of factionalism. Boucek [6] recognizes three forms ("faces") - cooperative, competitive, and degenerative factionalism - of which only the latter produces exclusively negative effects and outcomes for the party organization (collapses or splits). In contrast, cooperative factionalism has a consensus-building function and preserves sub-group identities, particularly in heterogeneous umbrella parties. The aim is internal consolidation and integration to avoid open conflicts that would increase the risk of a break-up. 
Competitive factionalism manages existing intra-party conflicts through diffusion strategies. The factions are opposed to each other, but the party provides for the institutional mechanisms (intra-party democracy, balance of power) to channel internal rivalries. Internal competition can be beneficial since it activates the rank and file and broadens the choice for the electorate. Still, it is a balancing act for a party since, "[w]ithout adequate safeguards, factional competition can become excessive. Hence, to keep factional pressures under control, leaders need to be vigilant to this risk (...)" ([6]: p. 476).

Boucek's functional perspective on factionalism followed a criticism by Belloni and Beller [2] that investigations of the issue had engaged mainly in the development of classification schemes for different types of factions (e.g., by [19, 28, 33, 58] that fail to account for factional dynamics and their consequences for the overarching organization (see also [6]: p. 468). On the conceptual level, Boucek's contribution marks an important step forward. However, the study of factionalism (still) suffers from an underdeveloped methodological level that complements the theoretical concepts with empirical measures. To do justice to the advanced state of the theoretical debate, the challenge is to find a measure that not only takes into account the number and size of party sub-groups but also considers the cohesion of the overall party as well as the cohesion within and between these sub-groups. As we rely on Janda's considerations on the topic, we also stick to his simple definition of cohesion "as the extent to which parties vote together" ([34]: p. 174), which basically relies on the general intuition of 'cohesion' used in many disciplines (physics, chemistry, social psychology etc.) referring to any kind of force/similarity that holds entities of a system together. But unlike Janda, and many other authors, the terminology we use is not confined to legislative voting, but refers to all kinds of explicated political beliefs, expressed e.g. in an opinion poll. ${ }^{a}$ This calls for an integrated measure of party coherence, which is composed of the two elements intuitively suggested by Janda: cohesion and factionalism [33, 34].

This observation leads to the second motivation for our contribution - the lack of an integrative measure of party coherence. Certainly, various single indices exist such as the effective number of factions [5], derived from the famous effective number of parties developed by Taagepera and Shugart [64], or widely-used legislative party unity measures such as the Rice index and its modified versions [1, 9, 16, 29, 56], which basically measure the extent to which a parliamentary party group votes in unison. Alternative analytical methods visualize intra-party heterogeneity on one or more ideological dimensions and interpret the distances between the estimated ideal points as a measure for ideological dissimilarity (e.g. [13, 26, 54, 55]). Finally, also the polarization research literature provides various potential measures to capture

a See further below for our mathematical definitions. Throughout this article we try to keep terminological questions as simple as possible. Moreover, we are fully aware that the literature further distinguishes between 'party unity' (as the most generic term), inherent 'cohesiveness', and enforced 'discipline' (see [7, 9, 25, 53]. We do not make this distinction here but simply assume that the survey data we analyze is a manifestation of party cohesion. 
party coherence, e.g. the dispersion of opinions measured by its variance, the degree of bimodality of the opinion distribution measured by its kurtosis, or the more elaborated Esteban-Ray polarization measure and its derivatives [17, 18, 20] that combine cohesion within and divergence between subgroups and are thus the most promising candidates for measuring party coherence.

While all these measures - single indices, spatial approaches, and polarization measures - prove to be adequate for the needs of legislative or party-system experts who are interested in the number and size of factions, the extent of party unity and ideological heterogeneity, or polarization between parties, they are insufficient for research on intra-party factionalism. This is immediately obvious in the case of Boucek's own index of the effective number of factions since this index does not provide any useful information about the dynamics between the factions (e.g. the three forms of factionalism proposed by Ref. [6]). Party unity indices are problematic, too, mainly because the average unity score does not tell much about the internal factional structure of a party. For instance, a Rice index value of 90.0 might indicate either that the party is highly united and the remaining five percent of the members of parliament (MPs) who, on average, vote against the party line is, in itself, a heterogeneous group, or that the dissenting five percent are on the verge of defection. $^{\mathrm{b}}$ Moreover, analyses based on legislative votes in parliamentary systems usually overestimate party unity because of peer pressure and disciplinary measures $[7,25]$ and, thus, are generally bad predictors of party splits. ${ }^{\mathrm{c}}$ Finally, polarization measures have been developed mainly to capture instabilities on the societal level, referring, e.g., to larger intra-party distances along the political left-right axis (e.g. [49]). Although some measures may be suitable to capture the smaller opinion divergence within a single party, we will show in this contribution (section 4.2.4.) that they fail to sketch an adequate picture of intra-party polarization, because not necessarily the heterogeneous parties are in higher risk of splitting.

Finally, the third motivation for our paper refers to a remarkable development in Swiss politics that makes this country an ideal test case for our measure: Although party mergers and splits are extreme and thus rare outcomes of party dynamics, especially in long-established, stable democracies, Switzerland has witnessed two party splits and one party merger within the last decade. This underlines the fact that, in the last 15 years, the Swiss multi-party system ${ }^{\mathrm{d}}$ has undergone major transitions $[37,45]$. The first major development concerned regrouping within the bourgeois party camp. The formerly cohesive and dominant bourgeois camp, consisting of the CVP (moderate Christian-democrats), the FDP (liberal Free Demo-

\footnotetext{
bIllustrative is the case of the German Social-democrats (SPD), often regarded as the most disciplined legislative party in the German parliament with Rice index scores of almost 100.0 [59]. The SPD still went through a severe internal crisis and eventually suffered a party split at the grassroots level in 2004.

${ }^{\mathrm{c}}$ Furthermore, the analysis of legislative votes is affected by data validity problems, especially in comparative settings [9, 10, 30, 52, 57].

d Between 2003 and 2012 there have always been 12-14 parties represented in Swiss parliament.
} 
cratic Party), the SVP (national-conservative Swiss People's Party), and the small Liberal Party (which merged with the FDP in 2008), was blown up by the SVP's strong accentuation of national-conservative standpoints, mainly regarding foreign and immigration policy. The party system, thus, developed into a triple-pole system of roughly a 30\% vote share each: left-wing parties - mainly the SPS (Socialdemocrats) and GPS (Green Party) -, right-wing parties (mainly the SVP), and a conglomerate of moderate-center parties (such as the CVP and FDP) [46]. In this system, the ideologically heterogeneous and also increasingly competitive political center regularly plays the role of legislative majority-builders by deciding whether they ally with the parties on the right or on the left $[32,36,61] .{ }^{\mathrm{e}}$ Within this change that can be described as a between-party-polarization, two party splits constitute a major development. In 2004, shortly after the 2003 general elections, center-turned members of the GPS seceded and founded the Green-Liberal Party (GLP) as a new political force positioned somewhere between the GPS and the CVP. Similarly, and as a direct consequence of the aforementioned first major development in the Swiss party system, some moderate members of the SVP separated in 2008 and formed the Bourgeois-Democratic Party (BDP), which now poaches in the preserves of the FDP and the CVP. In the same period, the FDP made a move in the opposite direction since the party merged with the LPS. To sum up, two parties suffered a split and one party has merged with a smaller one. Only the SPS and the CVP came through without internal splits or mergers.

Political observers see a distinct quality in the two party splits. While the secession of the Green-Liberals seems to be traced back to marked differences in ideological attitudes at the grass-roots level regarding the role of the state in environmental, economic, and welfare issues ${ }^{\mathrm{f}}$ [63], the SVP-BDP split seems more to be a consequence of widening discrepancies among party elites with respect to questions of political conduct (gentle vs. offensive conservatism) rather than of deep-rooted ideological disagreement [38]. Thus, the Green Party split may be characterized as a 'bottom-up' split, while the SVP split is more 'top-down'. This distinction refers to the localization of the driving forces within a party's organization that may lead to a split - i.e. either more on the level of 'ordinary' party members or even party sympathizers or more on the level of leading party figures, the party elite. However, this distinction is not disjunctive, as both mechanisms can be in play, although one of both could be predominant. Thus, the question emerges of how one could find a way to identify clear markers of either type of party split mechanism. We propose, that our measure of coherence would allow clarifying this distinction.

Summing up: To catch up with recent theoretical contributions in the field, to overcome longstanding shortcomings of existing measurement techniques, and to

e There is no stable parliamentary majority in the Swiss legislature, but ad hoc coalitions that form during a lawmaking process according to policy preferences at stake [36, 62, 61].

${ }^{\mathrm{f}}$ The GPS stands on the ground of a leftist, trade union-oriented ideology, while the GLP is based on moderate liberalism. 
get insight into very recent and dramatic changes within Swiss parties, this paper proposes a new measure of party coherence based on Janda's [33, 34] considerations which intuitively brought together the idea of cohesion and factionalism, but did not offer an integrated measure for it. The paper further provides for an empirical application of the measure in terms of a plausibility check for the results and offers some possible interpretations.

The paper proceeds as follows: The next two sections introduce and operationalize the measure of party coherence based on the superparamagnetic clustering procedure and link it to the theoretical concepts of party factionalism and party coherence cited above (the mathematical details of the clustering algorithm are outlined in the appendix). Afterwards, we will test this concept using survey data regarding the political positions of candidates in the run-up to the Swiss general elections of 2003 and 2007 (which avoids the aforementioned pitfalls of measuring based on legislative votes). We also check whether alternative measures deriving, in particular, from the polarization literature, are able to detect indications for party splits in the SVP and GPS. In the last section, the paper briefly discusses the results in light of recent developments in the Swiss party system, specifies some shortcomings and pitfalls of our approach, and assesses the potentials for future research.

\section{Physics Meets Politics: Superparamagnetic Clustering as a Measurement of Party Coherence}

In order to turn Janda's [33, 34] considerations of party coherence consisting of two dimensions into a defined quantitative concept the paper suggests the adaption of the concept of superparamagnetic clustering $[4,50]$ to analyze the internal organization of parties. Superparamagnetic clustering is a nonparametric method suitable for detecting and characterizing group structures in data without imposing a prior bias. The algorithm is inspired by a self-organization phenomenon in magnetic spin systems. In an inhomogeneous spin system, clusters of correlated spins can emerge, corresponding to groups of spins with strong couplings (i.e. strong interactions). Upon an increase in temperature, i.e. an increase in stress on the system, these clusters decay into smaller units in a cascade of (pseudo-)phase transitions, revealing the richness of the cluster structure of the system. Hence, the physical properties ('coherence') of the spin system are contingent on two factors: 1. stability of the largest cluster (the core cluster) under stress (the cohesion dimension); 2. diversity of the whole system in terms of cluster diversity (the factionalism dimension).

A translation of this picture into the world of political science yields the following correspondent: the spin system is the party organization, the single spins are the party members (i.e. their belief systems ${ }^{\mathrm{g}}$, if the coherence of the party is assessed under the perspective of the beliefs the party member holds), the spin couplings

gFollowing Converse, a belief system is a "configuration of ideas and attitudes in which the elements are bound together by some form of constraint or functional interdependence" ([14]: p. 207). 
reflect the similarity of their belief systems, and the temperature may be interpreted as an external stress factor (e.g., electoral decline) ${ }^{\mathrm{h}}$ that imposes more weight on disagreement among party members with respect to political issues (by, e.g., forcing them out of a party). The couplings are related to the distance matrix that reflects the mutual similarity between each pair of members. Hence the similarity matrix encodes the party structure and stability. The largest cluster represents the main core of a party. Its stability corresponds to the party cohesion (note that according to our notion, the term 'cohesion' reflects a stability property of the core cluster, whereas in a broader understanding in political science, cohesion is an analogue of the similarity - in beliefs, voting behavior, etc. - of the party members). The revealed cluster structure reflects the structure of internal factions (or sub-groups) of a party according to systematic differences in some political issues. This structure is captured by the notion of factionalism.

At this point, it is important to recall the purpose of resorting to physics: we use the spin model to introduce a measurement for the coherence of political beliefs. It is an analytical instrument, and, as such, it is neither intended to describe nor to explain the behavioral dynamics of party splits. Our measure claims only that it catches the state of the internal coherence of parties in two important dimensions as a mere prerequisite (and not a causal explanation) for a possible split. Thus, since we are neither modeling the split itself nor the forces which might lead to the split, we do not require to provide an exact correspondence between the parameters of the selforganization phenomenon (e.g., temperature), and the real social forces at work in a political party. In fact, superparamagnetic clustering has been applied for cluster analyses in many different fields (an overview is given in [50] and references therein) and can be described as a data analysis method without reference to spins. From this formal standpoint, the parameter $T$, interpreted as the system's temperature, is a resolution parameter that controls the granularity of the cluster detection process. However, the spin picture offers a convenient framework of conception.

Furthermore, the basic concept of the measure is in principle not dependent on the specific similarity metrics used. As we relate party coherence to the belief system of the party, we have chosen a similarity metrics that quantifies the disagreements of party members in respect of political issues. However, one may also analyze party coherence from a different perspective, e.g. by focusing on actual social interactions party members have and quantify this aspect. The problem under investigation and the theory behind the problem leads the choice of the similarity relation and makes the measure adaptable to different types of problems (see [12]).

With this two-dimensional quantification at hand we are able to establish an empirical link to what we have previously identified the core implication from Boucek's [6] theoretical work: high degrees of party factionalism do not necessarily mean high risks of party splits. Some parties are stable organizations even if (or because) they

${ }^{\mathrm{h}} \mathrm{Harmel}$ and Janda [23] consider external stimuli as very important factors contributing to party change. 


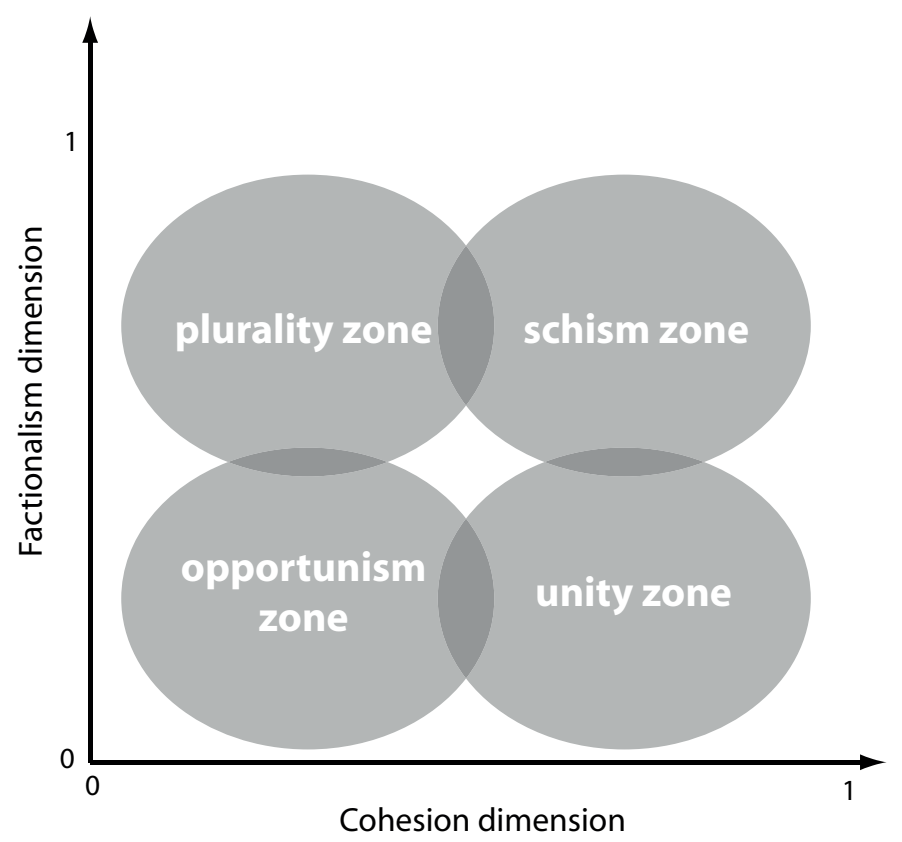

Fig. 1. Four ideal types of party coherence (the overlapping clusters indicate that these categories are not strictly defined and quantified).

are highly factionalized. Pivotal is instead the combination of the two dimensions, factionalism and cohesion. Translated into our own quantitative concept of party coherence, which is composed of two numeric values, we can identify four exemplary states of a party (Fig. 1): (1) low degrees of cohesion and factionalism: The members of such a party are only loosely associated and do not form cohesive sub-groups. The party constantly runs a risk of losing individual members as soon as stress increases ('opportunists') but, due to the fragmented internal structure, there is no reason to fear that an organized rebellion of any strong sub-group will cause a major split in the party. (2) High degrees of factionalism, low degrees of cohesion: the party exhibits a high plurality of sub-groups and lacks a strong and stable core ('plurality zone'). However, the couplings between the sub-groups are not significantly smaller than those within the sub-groups, diminishing the risk of splitting due to a high degree of factionalism. (3) Low degrees of factionalism and high degrees of cohesion may indicate a highly united party. All members are concentrated around a strong core ('unity zone'). (4) For any party, the most disquieting state is the combination of high degrees of factionalism and cohesion. The structure of the members' belief systems makes the party potentially vulnerable to a split, as two ore more strong sub-groups exist with strong couplings within the groups but low couplings between them ('schism zone'). 


\section{Coherence: Exposition of the Measure and Operationalization}

Our measure of coherence is based on superparamagnetic clustering (SPC, [4]) and sequential superparamagnetic clustering (SSC, [50]) - two algorithms whose technical details are outlined in the appendix. Based on these algorithms, we have defined a measure of coherence that captures both cohesion and factionalism of a party [11]. The cohesion component of the whole party $C_{c}$ is calculated in the SPC framework. It is evaluated with respect to the disintegration of the largest cluster $\bar{c}$ for increasing temperature $T$ until the system's order completely breaks apart, where $T$ is the parameter that models the stress on the system. This involves the assumption that the largest cluster represents the 'core' of the party that disintegrates under stress.

Let $C S(t)$ be the size of the core cluster for $T=t$. We assume that $C S(0)=n$, where $n$ stands for the total number of data points (i.e., all the party members); i.e., without stress, all the members are in the same cluster. Upon an increase in stress, $C S(t)$ decreases until $C S(t)=1$ for some $t=T_{\text {end }}$. The average decay curve serves as a measure of party cohesion.

$$
C_{c}=\frac{1}{T_{\text {end }}} \int_{0}^{T_{\text {end }}} \frac{C S(t)}{n} d t
$$

The measure is normalized to the interval $[0,1]{ }^{\mathrm{i}} C_{c}$ is close to 1 if the largest cluster remains intact for a long time and then disintegrates rapidly for high $T$, whereas $C_{c}$ is close to 0 if the largest cluster disintegrates rapidly and only a small core is stable over a longer interval. In the actual analysis, $C_{c}$ is calculated in $l+1$ discrete steps $t=0, \Delta T, 2 \Delta T, \ldots, T_{\text {end }}=l \Delta T$. For the approximate calculation of the integral, the trapezoidal rule, known from basic calculus, is used.

$$
C_{c}=\sum_{i=0}^{l-1} \frac{(C S(i \Delta T)+C S((i+1) \Delta T)}{2 n l}
$$

The factionalism component of coherence $C_{f}$ is calculated using SSC, yielding a binary tree in which the size of each of the $k$ sub-clusters is evaluated. Again, we consider the largest cluster $\bar{c}$ as the 'core' of the system. $C_{f}$ is calculated as the sum of the distance of each cluster $c_{i}$ from the largest cluster in the tree diagram weighted with its size $\left|c_{i}\right|$. The 'tree distance' $\bar{d}_{i}$ is the number of bifurcation points in the tree between $\bar{c}$ and $c_{i}$. Both the maximal tree distance $\bar{d}_{\text {max }}$ and the size of the largest cluster serve as calibration factors, leading to the definition:

$$
C_{f}=\sum_{i=1}^{k} \frac{\bar{d}_{i}}{\bar{d}_{\max }} \cdot \frac{\left|c_{i}\right|}{|\bar{c}|}
$$


$C_{f}$ is not normalized to 1 according to the current definition. Its value is 0 if SSC does not reveal any sub-clusters, and it is close to 0 if only small clusters emerge. However, many large clusters that have a large tree distance from the largest cluster lead to an increase in $C_{f}$. Since $C_{f}$ is typically far below the maximally possible value, the normalization was skipped to simplify the calculation.

In this way, the measure consisting of the two components $C_{c}$ and $C_{f}$ is able to capture the intuition of coherence outlined in Figure 1. It is important to recall the interrelation between these two dimensions: The distance matrix encodes the similarity between all party members and in this way reflects both the cohesion of the whole party (measured by $C_{c}$ ) as well as the cohesion within and between sub-groups - latter is then expressed by the cluster tree that emerges in the SSC paradigm. The concept was tested extensively and approved on the basis of toy data [11]. We now apply the measure using data that approximates the political beliefs of members of Swiss parties.

\section{An Application to the Swiss Party System}

The aim of the following section is to provide a plausibility check for the results of the new measure. The benchmark we use is the (scarce) literature and political commentary on recent development in the Swiss party system. We are not testing for alternative explanations since we are not establishing a causal model that could fully explain the occurrence of party splits.

\subsection{Data, Political Context, and Hypothetical Expectations}

Our data originate from the smartvote project, a Swiss vote advice application [66]..$^{\mathrm{j}}$ As a part of the project, all political candidates in the run-up to the Swiss general elections in 2003 and 2007 were invited to take part in a survey of about 70 questions designed to elicit the candidates' political positions on a broad range of issues. ${ }^{\mathrm{k}}$ For our project, we investigated the candidates of the five largest Swiss parties: the SVP (national-conservative Swiss People's Party), SPS (Social-democrats), FDP (liberal Free Democratic Party), CVP (Christian-democrats), and GPS (Green Party). The response rate was higher in 2007 (between $82-98 \%$ of all candidates of the five parties answered the questionnaire) than in 2003 (46-78\%), which points to the increasing relevance of the project since its launch (see Table 1). ${ }^{1}$ The questionnaire items were

\footnotetext{
${ }^{\mathrm{j}}$ Smartvote (http://www.smartvote.ch) is a widely used web-based vote advice application in Switzerland which has been developed and is operated by the non-partisan, non-profit association 'Politools' in Berne. It is based on the idea of preference matching; i.e., any smartvote user (voter) may answer the same set of questions as the candidates and then gets a list of candidates that indicates the political distance between the user and the candidates.

kThe survey comprised 70 questions in 2003 and 73 in 2007. In 2003, the smartvote tool was operational only in the German- and French-speaking parts of the country. It was extended to the Italian-speaking part in 2007.

${ }^{1}$ The use of candidate survey data that are made public in the run-up to elections may raise methodological concerns in two respects: first is data validity since the responses might be en-
} 
Table 1. Response rate to the smartvote questionnaire by (elected) candidates, 2003 and 2007: Number of candidates/elected MPs for which smartvote data was available, and percentage of total number of candidates/elected MPs.

\begin{tabular}{lllll}
\hline & $\begin{array}{l}2003 \\
\text { all candidates }\end{array}$ & elected candidates & $\begin{array}{l}2007 \\
\text { all candidates }\end{array}$ & elected candidates \\
\hline CVP & $223(67.6 \%)$ & $30(69.8 \%)$ & $327(85.8 \%)$ & $39(84.8 \%)$ \\
FDP & $308(70.2 \%)$ & $28(56.0 \%)$ & $459(91.8 \%)$ & $38(88.4 \%)$ \\
GPS & $140(51.1 \%)$ & $11(84.6 \%)$ & $372(87.3 \%)$ & $21(95.5 \%)$ \\
SPS & $286(77.9 \%)$ & $54(88.5 \%)$ & $404(96.0 \%)$ & $48(92.3 \%)$ \\
SVP & $184(46.5 \%)$ & $34(54.0 \%)$ & $343(81.7 \%)$ & $57(82.6 \%)$ \\
\hline
\end{tabular}

answered using a 4-point-Likert scale (strongly agree, agree, disagree, and strongly disagree), leading to the following distance function between two candidates $\mathrm{X}$ and $\mathrm{Y}$ of the same party with respect to this item: the possible answers are coded with 1 to 4 . If both agreed to a question, the resulting value is 0 , whereas the maximal value is 3 (strongly agree vs. strongly disagree, $|1-4|)^{\mathrm{m}}$. The sum of the absolute values for each question normalized with the number of answered questions is the distance between $\mathrm{X}$ and $\mathrm{Y}\left(\right.$ Manhattan distance metric) ${ }^{\mathrm{n}}$. The mutual comparison among all candidates of a party both in 2003 and 2007 results in a distance matrix that serves as input for the clustering algorithms.

This approach weighted each issue captured by the smartvote survey equally based on the rational that the items had been chosen to capture the most important issues present in the political discussion to which each party had distinct opinions. It could be the case that disagreements upon some issues may be of more importance for a specific party than disagreements upon other issues; this can be incorporated by putting more weight on these components in our distance function. However, this would have required an independent survey of the smartvote items with respect to party-specific relevance, which is beyond the scope of our plausibility analysis.

The smartvote project collects data at the level of individual candidates, which seems appropriate for several reasons: First, Swiss parties are organized along Switzerland's federalistic structure; i.e., they constitute bottom-up organizations

dogenous to party affiliations or voter preferences (see, e.g., [22]), and second is the completeness of the data (coverage of all relevant party sub-groups). While most survey data are prone to such problems, previous research with smartvote data may alleviate at least some of these concerns. E.g., Ref. [61] shows that, on average, $85 \%$ of the answers given by elected MPs in the pre-election survey correspond to their real legislative behavior. Moreover, the main reason that MPs deviate from their pre-election positions is incompatibility with the position of their legislative party group. Thus, endogeneity problems do not seem particularly worrying. Likewise, various inspections of the 2003 and 2007 data have shown that, of the five parties included in our analysis, all relevant sub-groups (party wings) are sufficiently covered.

m The 2007 survey contained ten questions related to public spending in various policy fields. These questions have only three answer options (more spending, as-is state, less spending); the maximum distance per question in these cases is 2 .

${ }^{n}$ Several distance metrics have been investigated. The Manhattan distance proved to be the simplest measure that revealed the most stable results. 
on the basis of local and cantonal parties [37] that are solely and exhaustively responsible for the nomination of candidates within their district. This fragmented structure cultivates regional disparities within the parties. Second, the voting system for the National Council follows open-list proportional representation in 20 of the 26 electoral districts (the remaining six are single-member districts that apply a first-past-the-post system). Voters are allowed to split their votes freely between candidates of different party lists; approximately $60 \%$ of the ballots cast are modified [44]. Third, Swiss legislators enjoy a considerable amount of political leeway since the executive-legislative relations follow, to a large extent, the logic of a separation-of-powers system [27, 39, 61, 62]. This, altogether, promotes the cultivation of personal, party-independent candidate profiles.

As outlined in the introduction, both the SVP and the GPS experienced a party split in the last decade, although political observers see a distinct quality in the two splits. This presumable distinct quality of the two party splits leads to the expectation that coherence between the belief systems among the pre-split SVP members is generally higher than that among pre-split GPS members. Furthermore, we expect a difference when we restrict the coherence analysis to the elected MPs as representatives of the 'true' party elite. There, we expect greater agreement among the GPS elites than among the SVP elites before the splits.

\subsection{Results of the Coherence Analysis}

\subsubsection{Sensitivity analysis}

Compared to other types of classification problems [51], our data sets did not display definite structure in terms of clear-cut, distinguishable sub-groups. Thus, a sensitivity analysis was necessary to assess the parameter space spanned by the calibration parameters of the clustering algorithm (these parameters allow for controlling the clustering sensitivity; see the appendix for details). The sensitivity analysis revealed a parameter (NT_steps, a number that controls the resolution of the $T$-axis into steps $\Delta T$ ) that is suited to characterize the statistical properties of the coherence measure, as a variation led to quasi-stable intervals (with respect to non-zero values of $C_{f}$ ) in the parameter space for each data set. Based on samples of parameter values from these intervals, $C_{c}$ and $C_{f}$ have been calculated for each party, leading to statistics for which the mean and standard deviation are displayed. The variability of $C_{f}$ was, in all cases, larger than the variability of $C_{c}$ (see standard deviations in Fig. 2). A direct comparison of all the parties under equal parameter settings for the algorithm is possible for, e.g., NT_steps $=220$ since this value was located in all the quasi-stable intervals.

\subsubsection{Overall party coherence}

The coherence analysis (Fig. 2) comparing the parties for the 2003 and 2007 elections confirms that the Swiss party system is formed by mostly non-coherent parties: 
While the unity zone was already virtually unoccupied in 2003 , there is an increasing tendency in 2007 for further crowding in the opportunism zone.

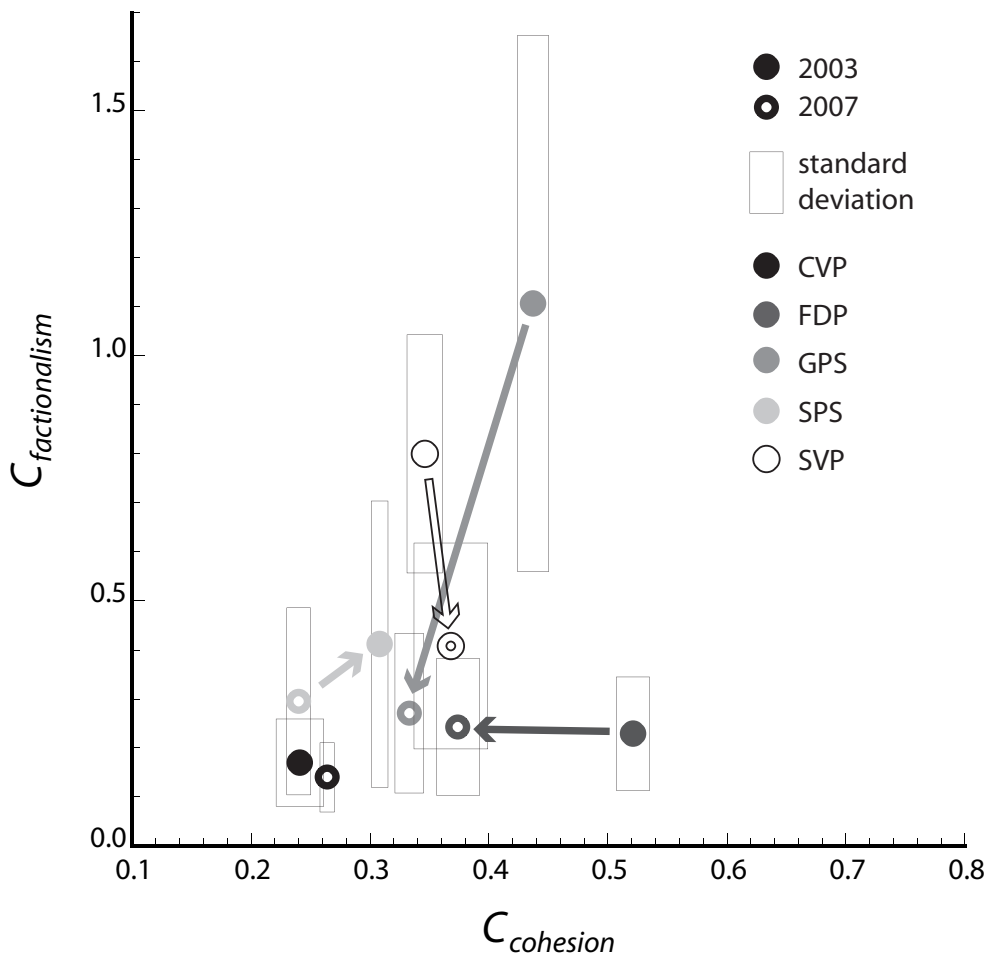

Fig. 2. Coherence analysis for Swiss parties based on the candidates of national elections 2003 and 2007.

However, the comparison between the 2003 and 2007 elections reveals some interesting developments with regard to the focus cases of the analysis, the GPS, SVP and FDP: first, the largest change in terms of cohesion and factionalism can be observed within the GPS. In 2003, the party was located around the schism zone but left it for the opportunism zone in 2007, mainly due to a distinct reduction in the factionalism dimension of the coherence measure. Second, the candidates of the SVP tended in 2003 toward the plurality zone; i.e., the party was characterized by a collection of identifiable subgroups which exhibited sufficiently strong betweengroup couplings to avoid the risk of a split. The number and strength of these subgroups decreased until 2007. Consequently, the SVP moved into the opportunism zone, quite close to the border area of the unity zone. Third, the most 'monolithic' party was the FDP in 2003, which, however, lost this property in 2007. In our analysis for 2007, we anticipated the merger between the FDP and LPS and tied the candidates of the two parties together since it was already clear back then 
that they would combine forces in the very near future. Other than what could be intuitively concluded from the analysis, the merger is not responsible for the decrease in cohesion because the move to the left in Figure 2 also appears when we calculate the coherence of FDP candidates alone; it is the factionalism dimension that was mainly increased by the merger. Fourth, the SPS dived deeper into the opportunism zone between 2003 and 2007, while, with the CVP, hardly any changes can be observed; this party kept a stable position deep in the opportunism zone.

In the face of the splits and mergers that have occurred within the GPS, SVP, and FDP, the results in Figure 2 are not unexpected and will be further scrutinized below with regard to differences between the coherence of the belief systems among all candidates (rank and file) and the coherence within the selection of elected MPs (top elite of the party). ${ }^{\circ}$ Two outcomes of the coherence analysis are particularly surprising for scholars of the Swiss party system: the high coherence among FDP members in 2003 and the quite incoherent state of the SPS at both measuring points. In the latter case, the popular picture of a highly united legislative party obviously does not match the true heterogeneity of the party members' belief systems.

\subsubsection{Comparing candidates with elected MPs}

In the second step, we compared $C_{c}$ and $C_{f}$ of the parties with the corresponding values of the elected MPs of each party. ${ }^{\mathrm{p}}$ In this way, we can investigate the extent to which the coherence of the elected MPs (representing the 'elite' of each party) reflects the coherence in the field of all candidates (representing the rank and file). We restrict our analytical focus here to the three cases that have undergone splits or mergers since 2003 (the GPS, SVP, and FDP). Figure 3 reveals three very different patterns. First, in both 2003 and 2007, the SVP elite was closer to the schism zone than the party's rank and file, which confirms the characterization of a 'top-down' split of the party in 2008. In contrast, the coherence analysis of all SVP candidates would not have led to the conclusion that a party split was imminent. Second, the analysis of the Green Party depicts a marked difference from the other parties. The GPS elite in 2003 is clearly located in the unity zone, while the coherence analysis of the party's rank and file signals an imminent party split at the grassroots level (which, indeed, materialized in 2004). The ideological diversity among

\footnotetext{
'In our analysis, elected MPs form the 'top' of the party while the mass of all running candidates forms the 'bottom'. This seems reasonable in the Swiss context due to the aforementioned fragmented intra-party structures and the fact that Swiss parties, compared to their foreign counterparts, cultivate a more inclusive, less hierarchical organizational structure even at the national level.

"PFor $C_{c}$, we investigated the values of temperature $T$ at which the elected candidates 'left' the main cluster for increasing $T$, leading to a value of $C_{c}$ for the elected candidates in relation to the decay behavior of all party members. For $C_{f}$, we took the binary tree of the whole party as the structure of the network and determined where in the network the elected candidates are located, leading to a value of $C_{f}$ for the elected candidates in relation to the network structure of the whole party.
} 
party members obviously had no equivalent representation in the party elite. In 2007, after the party split, the situation completely reversed. Now, the party elite (which also increased from 13 MPs in 2003 to 22 in 2007) is much closer to the schism zone, while another 'bottom-up' split coming from the rank and file seems unlikely. Finally, regarding the FDP, the party elite both in 2003 and 2007 was closer located to the unity zone than the rank and file. The 2007 figures, which comprise the combined data for FDP and LPS candidates, further confirm the higher internal diversity produced by the merger.

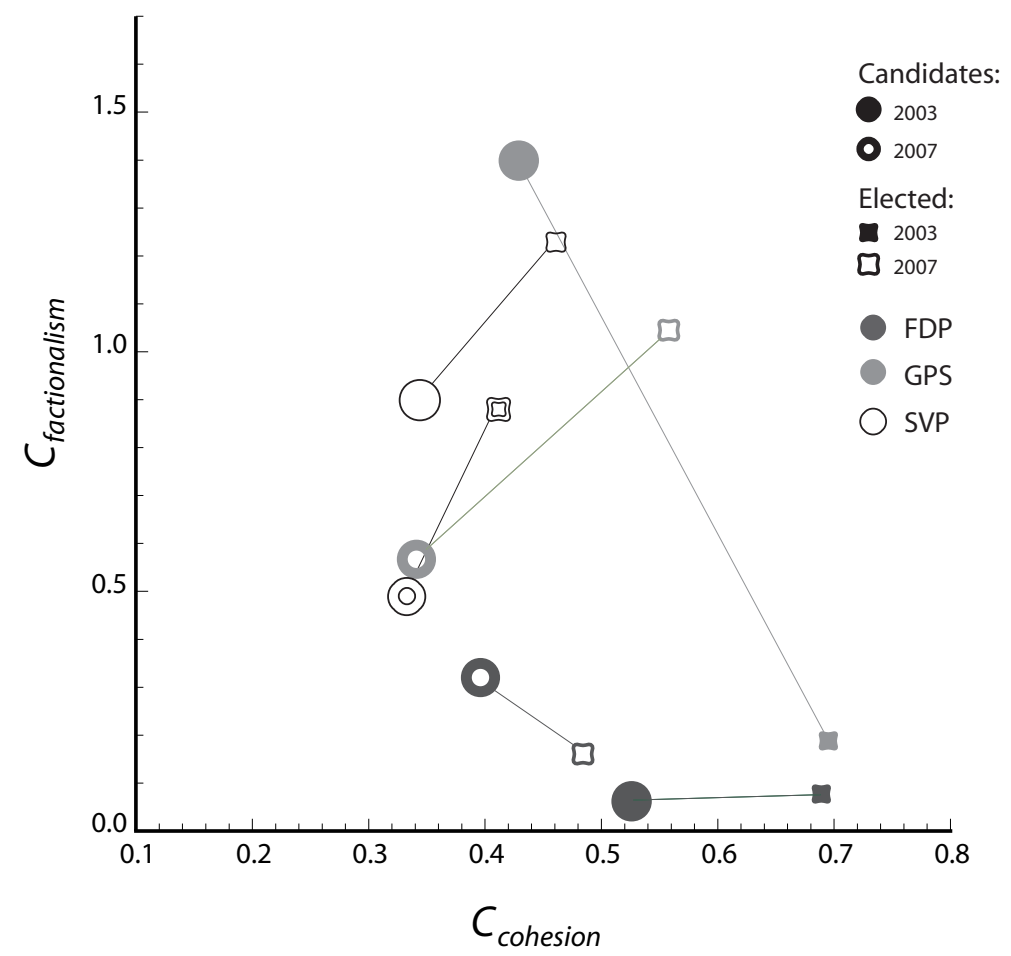

Fig. 3. Coherence analysis for Swiss parties' candidates and elected MPs for FDP, GPS and SVP.

The differences between GPS and SVP regarding the coherence of all party candidates versus their elites are analyzed in more detail by referring to the network (Fig. 4). The aim is to see whether we find additional evidence for the qualitatively distinct party splits of GPS and SVP, especially regarding the claim that the GPS-GLP split in 2004 was based on deep-rooted ideological differences while the SVP-BDP split in 2008 occurred due to disagreement regarding questions of political conduct among party elites. In 2003, the GPS displayed five clusters in the SSC paradigm. The largest cluster is represented by 8 elected candidates, and two additional candidates emerge from the cluster with the closest network dis- 
tance from the largest cluster. The second-largest cluster, however, not only has the largest network distance from the main cluster but also contains the elected MP Martin Bäumle, who was the driving force behind the breakup of the Green Party in 2004. The network analysis, thus, reveals that a significant portion of the party candidates had different opinions than the elite but was represented by only one person at the elite level. This explains the large differences in $C_{c}$ and $C_{f}$ for the party candidates versus the elected candidates in Figure 3.
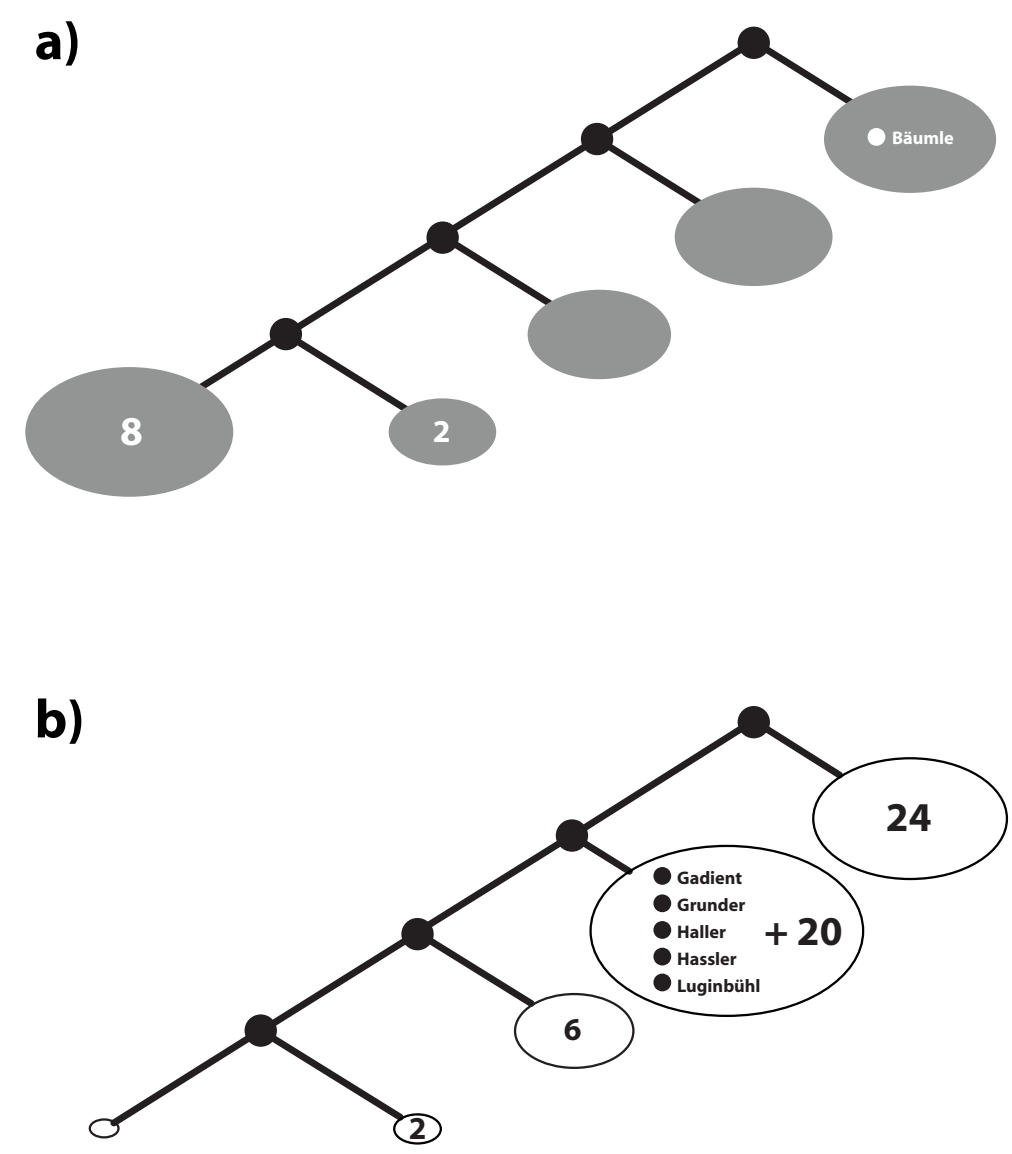

Fig. 4. Network topology for the GPS in 2003 and the SVP in 2007 (at NT_steps $=220$ ), indicating the distribution of elected candidates (numbers in clusters indicate how many elected candidates are in the cluster) and the location of 'schisma-exponents' (the area of each cluster scales with the number of party members who belong to this cluster).

For the SVP, the situation is different: in 2007, the network topology is similar to that of the GPS but, in quantitative terms, the network distances between the large clusters are much smaller. Furthermore, all five elected candidates who left the 
party during the split of 2008 were part of the main cluster; i.e., they did not differ significantly from the ideological core of the party. This indicates that the SVP indeed experienced a different type of party split than the Green Party: While, in the latter case, the defecting elite members showed a distinct belief system, the party split in the former case cannot be explained by incompatible belief systems.

\subsubsection{Comparing with alternative measures}

Our plausibility analysis using our coherence measure detects the later split of GPS and SVP and puts the notion of 'bottom-up' and 'top-down' party splits in a quantified framework. This raises the question whether existing measures are also able to serve this purpose. Of particular interest are measures emerging from polarization research, as for example Esteban and Ray characterize polarization with three features -1) there must be a high degree of homogeneity within each group; 2) there must be a high degree of heterogeneity across groups, and 3) there must be a small number of significantly sized groups ([20]: p. 824) - that have a close connection to our understanding of coherence. In particular, this definition matches with our characterization of the 'schism zone' in our coherence diagram, where indeed high polarization can be expected.

Polarization research offers various measures [21]. One family of measures attempts to describe polarization as separation/clustering over distributions with arbitrary numbers of groupings - the most prominent example of such a measure has been presented by Esteban and Ray (ER polarization measure, [20]). A second set of measures treats polarization as fundamentally a two-group phenomenon. A third approach, that does not necessarily require predefined groups, involves measures (or their combinations) that assess, e.g., the dispersion (measured by variance) or the bimodality (measured by kurtosis) of the belief distribution (e.g., [17]). Usually, those measures are applied to analyze polarization among pre-established groups (e.g., rich vs. poor, inter-party polarization; [49]) and they do this in referring to only one measurement dimension (e.g., income or position along the political leftright dimension). This leads to specific challenges when those measures are applied to intra-party polarization, where sub-groups are fuzzy, not necessarily known a priori, and characterized by a multitude of dimensions. In the following, we will apply selected polarization measures to our data set. When a measure reveals a high polarization value for a specific party compared to other parties, we consider this as an indication that the party may be polarized (and thus be in risk of splitting), and when a party shows a significant drop in polarization from 2003 to 2007, this may indicate a party split (i.e., a drop-out of polarizing opinions and potentially members that hold this opinion).

A first approach (method A in Table 2) is to identify single issues that show clear polarization among the party members. In our data set, agreement or disagreement to specified issues is measured using a 4-point Likert-scale. Following the suggestion of Di Maggio et al. [17], a negative kurtosis of the distribution along the agreement- 
Table 2. Comparison of alternative measures for intra-party polarization with our coherence measure.

\begin{tabular}{|c|c|c|c|c|c|c|c|c|c|c|c|c|c|}
\hline \multirow[t]{3}{*}{ Method } & \multicolumn{10}{|c|}{ Result per party } & \multirow{2}{*}{\multicolumn{3}{|c|}{ Suggestions }} \\
\hline & \multicolumn{2}{|c|}{ CVP } & \multicolumn{2}{|c|}{ FDP } & \multicolumn{2}{|c|}{ GPS } & \multicolumn{2}{|c|}{ SPS } & \multicolumn{2}{|c|}{ SVP } & & & \\
\hline & 2003 & 2007 & 2003 & 2007 & 2003 & 2007 & 2003 & 2007 & 2003 & 2007 & split & in risk & stable \\
\hline A & \multirow{2}{*}{\multicolumn{2}{|c|}{$-7^{13}$}} & 14 & 17 & 3 & 2 & 3 & 2 & 17 & 16 & CVP & FDP & GPS \\
\hline Trend & & & \multicolumn{2}{|c|}{3} & \multicolumn{2}{|c|}{-1} & \multicolumn{2}{|c|}{-1} & \multicolumn{2}{|c|}{-1} & & SVP & SPS \\
\hline $\mathrm{B}(\mathrm{K})$ & -.565 & .008 & .198 & .353 & .889 & .456 & 2.04 & 1.38 & 1.25 & .377 & CVP & (SVP) & FDP \\
\hline B (V) & .177 & .156 & .160 & .161 & . 140 & .121 & .127 & .121 & .067 & .114 & & & (GPS) \\
\hline Trend & \multicolumn{2}{|c|}{$.573 /-.021$} & \multicolumn{2}{|c|}{$.155 / .001$} & \multicolumn{2}{|c|}{$-.433 /-.019$} & \multicolumn{2}{|c|}{$-.651 /-.006$} & \multicolumn{2}{|c|}{$-.877 / .047$} & & & (SPS) \\
\hline $\mathrm{C}(\mathrm{K})$ & -.893 & -.288 & .321 & -.534 & 4.73 & 1.51 & 2.44 & 1.46 & 1.44 & 1.38 & CVP & FDP & GPS \\
\hline $\mathrm{C}(\mathrm{V})$ & .075 & .019 & .028 & .035 & .025 & .019 & .016 & .031 & .045 & .021 & & & SVP \\
\hline Trend & \multicolumn{2}{|c|}{$.605 /-.056$} & \multicolumn{2}{|c|}{$-.855 / .007$} & \multicolumn{2}{|c|}{$-3.22 /-.006$} & \multicolumn{2}{|c|}{$-.979 / .015$} & \multicolumn{2}{|c|}{$-.059 /-.024$} & & & (SPS) \\
\hline $\mathrm{D}$ & .052 & .025 & .007 & .015 & .085 & .041 & .064 & .073 & .057 & .088 & GPS & SVP & FDP \\
\hline Trend & \multicolumn{2}{|c|}{-.027} & \multicolumn{2}{|c|}{.008} & \multicolumn{2}{|c|}{-.044} & \multicolumn{2}{|c|}{.009} & \multicolumn{2}{|c|}{.031} & & SPS & $(\mathrm{CVP})$ \\
\hline \multirow{2}{*}{$\begin{array}{l}\text { E } \\
\text { Trend }\end{array}$} & .722 & .777 & .798 & .884 & .942 & .932 & .903 & .926 & .815 & .853 & (FDP) & (CVP) & SPS \\
\hline & \multicolumn{2}{|c|}{.055} & \multicolumn{2}{|c|}{.086} & & & & & & & & & $\begin{array}{l}\text { GPS } \\
\text { SVP }\end{array}$ \\
\hline $\begin{array}{l}\text { Cohere } \\
\text { (overall }\end{array}$ & $\begin{array}{l}\text { ce Ana } \\
\text { party c }\end{array}$ & $\begin{array}{l}\text { sis } \\
\text { herence }\end{array}$ & and co & nparin & candic & tes wit & electe & MPs) & & & $\begin{array}{l}\text { GPS } \\
\mathrm{SVP}^{b}\end{array}$ & $\mathrm{SVP}^{a}$ & $\begin{array}{l}\text { CVP } \\
\text { CVP } \\
\text { SPS }\end{array}$ \\
\hline $\begin{array}{l}\text { Real wo } \\
\text { (the SV }\end{array}$ & ld & lit shor & ly after & the 20 & elect & & & & & & GPS & SVP & $\begin{array}{l}\text { CVP } \\
\text { FDP } \\
\text { SPS }\end{array}$ \\
\hline
\end{tabular}

Note: Method A: Single issue polarization measured by the number of polarizing issues per party. Method B: leftright polarization measured by the kurtosis $(\mathrm{K})$ and variance $(\mathrm{V})$ of the distribution. Method C: Polarization in opinion space measured by the kurtosis $(\mathrm{K})$ ad variance $(\mathrm{V})$ of the distance distribution. Method D: Polarization of pre-defined sub-groups using the Esteban-Ray polarization measure (the measure involves a parameter $\alpha$ that can be interpreted as the polarization sensitivity of the measure. We used several settings for $\alpha$; the results did not differ qualitatively. Here we display the result for $\alpha=1$ ). Method E: Agreement index in legislative votes, own calculations of data provided by the Swiss Parliamentary Services. 'Trend' indicates the difference of the measures for 2007 and 2003. If a suggestion is arguable for a specific party, the party name is in brackets.

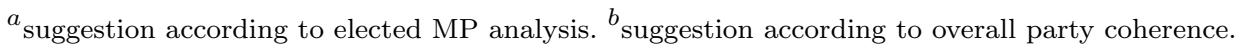

disagreement dimensions per issue can indicate polarization. ${ }^{\mathrm{q}}$ A straightforward polarization measure is then to count the number of issues with bimodal distribution and negative kurtosis per party. The results (Table 2, first row) reveal that in CVP, FDP and SVP a much higher number of polarizing issues is discernible compared to GPS and SPS, whereas CVP was able to significantly reduce this number. This would suggest that CVP may have undergone a split, and that FDP and SVP are in risk of splitting.

${ }^{\mathrm{q}} \mathrm{A}$ maximal bimodal distribution has a kurtosis of -2 ; a normal distribution has a kurtosis of 0 . However, a negative kurtosis alone is not a sufficient condition for bipolarity, as flat distributions have a negative kurtosis, too. Bimodality of the distribution has therefore to be checked independently. 
A second approach (method B) is to analyze data aggregated to represent the left-right dimension - a common approach in party polarization research (e.g. [49]). Also Swiss politics can be arranged along the political left-right axis [3, 31] and political positions in Switzerland can be reduced to a one-dimensional representation of the political space. We applied the correspondence analysis (CA) technique [48] $]^{\mathrm{r}}$ to extract the coordinates of the candidates along the left-right axis. This measure does not reveal clearly identifiable groups within the party (which is not surprising), although the distributions differ. To assess polarization, we use the combination of dispersion and kurtosis (partly following the suggestion of Di Maggio et al. [17]). Parties with more negative kurtosis and higher dispersion compared to others would then be more polarized. The results (Table 2, second row) reveal that CVP is most likely to have experienced a split. SVP, SPS and, to a lesser extent, GPS show a reduction in kurtosis when comparing 2003 with 2007 - but the kurtosis is still positive. Combined with the dispersion measure, only for the SVP a significant increase is detectable, which may indicate a risk for a split for the SVP.

A third approach (method $\mathrm{C}$ ) is to investigate the distribution of the partymember distances, i.e. the same input our algorithm uses. This data reflects the distribution of the party within the opinion space - and sub-structures within the party should show up in a bimodal (or multi-modal) distance distribution, as several scales should be present. Following the same rational as above, the results (Table 2 , third row) reveal that CVP is most likely to have experienced a split and FDP is most likely to be in risk of splitting.

A fourth approach (method D) is to identify sub-groups within each party and then to apply the uni-dimensional Esteban-Ray polarization measure. Given our data, this approach thus requires two preparatory steps: group identification and dimension-reduction. As we compare this measure with our approach, we use the same groups (identified at $N T$ _steps $=220$ ) and we aggregate the data in order to represent the left-right-dimension as outlined above. The mean position on the leftright dimension per group is the common policy position of this group. Using this measure reveals the following result (Table 2, fourth row): The highest polarizations are detectable for SVP, GPS and SPS, whereas a significant drop from 2003 to 2007 is discernible for GPS. This measure thus suggests that GPS most likely experienced a split, and that SVP and SPS are in risk of splitting.

Finally (method E), following the earlier suggestions of relating party unity to voting behavior of party members in parliament (see Introduction), we compare our result with party unity scores in the legislative years 2003 and 2007 using the Agreement Index developed by Ref. [29] ( 1 = voting in unison, $0=$ votes evenly split). The reported scores in Table 2 (see also similar results in Refs. [39, 60, 62]) reveal that those parties that actually split display high internal unity.

${ }^{\mathrm{r}} \mathrm{CA}$ is based on two analytical steps: 1) calculation of weighted Euclidean distance (chi-square distance) between the answer profiles of the candidates; 2) dimension reduction (factorization) using singular value decomposition. 
In summary, we have shown that all alternatives failed to adequately describe the actual development of the Swiss party system with respect to party splits. The Esteban-Ray polarization measure provided the best approximation; however, it wrongly identifies also the SPS as a 'split candidate'. Furthermore, it does not offer any additional instrument to analyze further the different characters of the GPS and SVP splits, as it does not include a perspective on the network of the parties. Finally, it requires substantial preprocessing (group identification and dimension reduction) in order to be applicable to the given data.

\section{Discussion and Conclusions}

Based on recent progress in the theoretical and case study-based research on party factionalism and the finding that the methodological tools to catch up with the current state of theoretical research are still lacking, we introduced a novel measure of party coherence that expands the classic conceptions of party unity on two dimensions and allows additional insights on how intra-party structures of belief systems can affect the risk of a party split. This measure of party coherence is inspired by a self-organization phenomenon in magnetic spin systems and adapts the methodological concept of superparamagnetic clustering to political science. In principle, the measure allows to include different potential mechanisms that may be responsible for party splits, whereas these mechanisms are integrated in the measure by choosing the type of similarity between party members considered as relevant. For our analysis, we have chosen to focus on the similarity of political beliefs party members have, as there is a rich tradition in political science that relates party unity and factionalism to the political issues parties stand for.

Taking the example of the Swiss party system between 2003 and 2007, the paper checked the validity and plausibility of the new measure's results against the conventional wisdom of political observers. The results of our still preliminary analysis are encouraging at least. They not only conform to the notion of Swiss parties as generally non-unitary, federally organized entities, which is manifested in the heterogeneous belief systems of party members, but they also confirm the analytical potential of the measure of party coherence since we could disentangle distinct types of party splits in a more precise manner: 'bottom-up' splits driven by divisions among the rank and file and 'top-down' splits driven by divisions among the party elites. Furthermore, the results of our analysis correctly located (according to the view of political observers) the rank and file of the Green Party in 2003 as well as the SVP party elites in 2003 and 2007 in the schism zone of the measure.

The purpose of the paper was to introduce a new measure of party coherence and provide a preliminary check for the plausibility of its results. It did so by using the data from a broad-based survey about the issue positions of candidates in the runup to the 2003 and 2007 general elections in Switzerland. The surveys of 2003 and 2007 are not completely equivalent. However, this is not decisive for the coherence analysis, as it is not the survey data itself that is compared over time but the 
inner coherence of the beliefs that the party members hold relative to each survey. As the surveys for both years capture similar and a wide range of political topics (although sometimes with different questions), the assumption that the comparison of the coherence values between 2003 and 2007 is valid does not seem unreasonable. But given the fact that this is the first application of the measure to behavioral data in social science there could and should be more emphasis put on the quality of the analyzed data in future research.

Our analysis has included the comparison of our new measure with a number of existing measures, mainly from the polarization literature. None of these existing measures detected the correct combination of party splits, split risks, and stable parties. To our understanding, the main reason for their empirical inferiority results from the fact that the theoretical concepts of polarization measures do not incorporate the notion of stability but (mis-)interpret internal diversity mostly as polarization. Furthermore, simple measures like kurtosis and variance that basically analyze one-dimensional distributions are inappropriate for intra-party polarization, as the dimension reduction blurs subtle but relevant structure in the data. The differences among groups within parties are much less clear compared to classical applications of polarization measures that cover the whole political spectrum. Applying more sophisticated measures like the Esteban-Ray polarization measure therefore require preprocessing of the data in order to both to identify relevant groups and to reduce the dimensionality of the data set. Our approach, in contrary, uses the multi-dimensionality as an asset, as the robust self-organization process of SPC intrinsically leads to enhancement of important dimensions while noisy/unimportant dimensions are suppressed. In this way, group identification and coherence measurement can be realized within the same framework.

There are a number of shortcomings in our approach (see also footnote 1). The main to consider is the legitimacy and validity of the similarity metrics chosen for a coherence analysis. Regarding legitimacy, the similarity relation must be backed both by theoretical insight and empirical support. Although, given the vast literature using political positions to analyze party unity questions, there is enough reason to give political beliefs of party members an important role for party coherence, they do not capture all relations between party members that may be decisive for the party's internal structure. In particular, social behavior based on personal relations, sensitivities, or animosities is not taken into account at all. In principle, the methodology would allow integrating more aspects of similarity and - for exploratory purposes - analyzing their mutual contribution to the coherence result by weighting them differently. However, this would require solid data capturing this similarity, which refers to a next pitfall of this methodology. As the similarity has to be quantified, this quantification must itself be validated properly. In our case, this issue is relevant as the political parties may be tempted to apply disciplinary measures to ensure their candidates giving uniform answers to the smartvote questionnaire. Furthermore, our data relied solely on the candidates, i.e. neither internal mechanisms of candidate selection nor the political beliefs of those not aspiring to 
candidateship are captured.

Besides the overcoming of the aforementioned shortcomings, we see three steps for future research to the newly proposed measure: first, subsets of the survey questions (individual policy areas or ideological dimensions) could be analyzed to get an idea of the policy-dependence of intra-party coherence. Second, as we have seen that the investigation of legislative party unity on the basis of parliamentary votes of elected MPs and the new measure of party coherence on the basis of preelection surveys among all candidates produce different results, the application of the coherence analysis to legislative data would be instructive. Third, the measure of party coherence could be utilized for a comparative analysis across party systems. For the application of the coherence measure in an international comparison of different party systems, the survey questions do not need to be identical. It would suffice to have available for each country a broad-based questionnaire that captures the major issues and political dimensions of the respective countries and covers a representative number of party candidates (or members) to produce new empirical insights regarding the belief system-based intra-party structures.

\section{References}

[1] Attinà, F., The Voting Behaviour of the European Parliament Members and the Problem of Europarties, European Journal of Political Research 18 (1990) 557-79.

[2] Belloni, F. P., and Beller D.C., Faction Politics: Political Parties and Factionalism in Comparative Perspectives (ABC-Clio, Santa Barbara CA, 1978).

[3] Benoit, K., and Laver, M., Party Policy in Modern Democracies (Routledge, London/New York, 2006).

[4] Blatt, M., Wiseman S., and Domany E., Superparamagnetic clustering of data, Physical Review Letters 76 (1996) 3251-4.

[5] Boucek, F., The Structure and Dynamics of Intra-Party Politics in Europe, in PanEuropean Perspectives on Party Politics, eds. Webb P., and Lewis P. (Brill, Leiden, 2003), pp. 55-95.

[6] Boucek, F., Rethinking Factionalism: Typologies, Intra-Party Dynamics and Three Faces of Factionalism, Party Politics 15 (2009) 455-85.

[7] Bowler, S., Farrell, D.M., and Katz, R.S., Party Cohesion, Party Discipline, and Parliaments, in Party Discipline and Parliamentary Government, eds. ibid (Ohio State University Press, Columbus, 1999), pp. 3-22.

[8] Carey, J.M., Competing Principals, Political Institutions, and Party Unity in Legislative Voting, American Journal of Political Science 51 (2007) 92-107.

[9] Carey, J.M., Legislative Voting and Accountability (Cambridge University Press, Cambridge, 2009).

[10] Carrubba, C.J., Gabel, M., Murrah, L., Clough, R., Montgomery, E., and Schambach, R., Off the Record: Unrecorded Legislative Votes, Selection Bias and Roll-Call Analysis, British Journal of Political Science 36 (2006) 691-704.

[11] Christen, M., Starostina, T., Schwarz, D., and Ott T., A spin-based measure of the coherence of belief systems, in Proceedings of NDES 2009 (Rapperswil, Switzerland, 2009).

[12] Christen, M., and Ott T., Quantified coherence of moral beliefs as a predictive factor for moral agency, in What Makes us Moral?, ed. Musschenga, B. (Springer. New York, in press). 
[13] Clinton, J., Jackman S., and Rivers D., The Statistical Analysis of Roll Call Data, American Political Science Review 98 (2004) 355-70.

[14] Converse, P.E., The Nature of Belief Systems in Mass Publics, in Ideology and Discontent, ed. Apter D.E. (Free Press, New York, 1964) pp. 206-61.

[15] Daalder, H., The Comparative Study of European Parties and Party Systems: An Overview, in West European Party Systems, eds. Daader, H., and Mair, P. (Sage, Beverly Hills CA, 1983) pp. 1-27.

[16] Desposato, S.W., Correcting for Small Group Inflation of Roll-Call Cohesion Scores. British Journal of Political Science 35 (2005) 731-44.

[17] DiMaggio, P., Evans, J., and Bryson B., Have American's Social Attitudes Become More Polarized? American Journal of Sociology 102 (1996) 690-755.

[18] Duclos, J.-Y., Esteban, J. and Ray D., Polarization: Concepts, Measurement, Estimation. Econometrica $\mathbf{7 2}$ (2004), 173772.

[19] Duverger, M., Les partis politiques (Armand Colin, Paris, 1954).

[20] Esteban, J.-M., and Ray, D., On the Measurement of Polarization, Econometrica 62 (1994) 819-51.

[21] Esteban, J.-M., and Ray, D., Comparing Polarization Measures. In Oxford Handbook of the Economics of Peace and Conflict, eds. Garfinkel M., and Skaperdas, S. (Oxford University Press, Oxford, 2011) pp 127-51.

[22] Griffin, J.D., Measuring Legislator Ideology, Social Science Quarterly 89 (2008) 337350.

[23] Harmel, R. and Janda K., An Integrated Theory of Party Goals and Party Change, Journal of Theoretical Politics 6 (1994) 259-87.

[24] Harmel, R,, Heo, U., Tan A., and Janda K., Performance, Leadership, Factions and Party Change: An Empirical Analysis. West European Politics 18 (1995) 1-33.

[25] Hazan, R.Y., Does Cohesion Equal Discipline? Towards a Conceptional Delineation. in Cohesion and Discipline in Legislatures. Political Parties, Party Leadership, Parliamentary Committees and Governance, eds. ibid (Routledge, London/New York, 2006) pp. 1-11.

[26] Heckman, J.J., and Snyder J.M., Linear Probability Models of the Demand for Attributes With an Empirical Application to Estimating the Preferences of Legislators, Rand Journal of Economics 28 (1997) 142-89.

[27] Hertig, H.-P., Party Cohesion in the Swiss Parliament, Legislative Studies Quarterly 3 (1978) 63-81.

[28] Hine, D., Factionalism in West European Parties: A Framework for Analysis, West European Politics 5 (1982) 36-53.

[29] Hix, S., Noury, A., and Roland G., Power to the Parties: Cohesion and Competition in the European Parliament, 1979-2001, British Journal of Political Science 35 (2005) 209-34.

[30] Hug, S., Selection Effects in Roll Call Votes, British Journal of Political Science 40 (2010) 225-35.

[31] Hug, S. and Schulz T., Left-Right Positions of Political Parties in Switzerland, Party Politics 13 (2007) 305-30.

[32] Hug, S., and Sciarini, P., Parties and their success in Swiss parliament. in Demokratie als Leidenschaft. Planung, Entscheidung und Vollzug in der schweizerischen Demokratie, eds. Vatter, A., Varone F., and Sager F. (Haupt Verlag, Bern, 2009) pp. 117-38.

[33] Janda, K., Political Parties: A Cross-National Survey (The Free Press, New York, 1980).

[34] Janda, K., Comparative Political Parties: Research and Theory, in Political Science: 
The State of the Discipline II, ed. Finifter, A.W. (American Political Science Association, Washington DC, 1993) pp. 163-91.

[35] Katz, R.S., and Mair P., Introduction, in Party Organizations. A Data Handbook, eds. ibid (Sage, London, 1992) pp. 1-20.

[36] Kriesi, H., The Federal Parliament: The Limits of Institutional Reform, West European Politics 24 (2001) 59-76.

[37] Ladner, A., Political Parties, in Handbook of Swiss Politics, eds.Klöti, U., Knoepfel, P., Kriesi, H., Linder, W., Papadopoulos Y., and Sciarini P. (Neue Zürcher Zeitung Publishing, Zürich, 2007) pp. 309-34.

[38] Ladner, A., and Fivaz J., Das Klischee der "liberalen" SVP-Kantonalparteien. Grosse Geschlossenheit der SVP in den Kernfragen, Neuer Zürcher Zeitung (22 April 2008) 18 .

[39] Lanfranchi, P., and Lüthi R., Cohesion of Party Groups and Interparty Conflict in the Swiss Parliament: Roll Call Voting in the National Council, in Party Discipline and Parliamentary Government, eds. Bowler S., Farrell D.M., and Katz R.S. (Ohio State University Press, Columbus, 1999) pp. 99-120.

[40] Laver, M., and Schofield N., Multiparty Government: The Politics of Coalition in Europe (Oxford University Press, London, 1990).

[41] Laver, M., and Shepsle K.A., Government Coalitions and Intraparty Politics, British Journal of Political Science 20 (1990) 489-507.

[42] Laver, M., and Shepsle K.A., Making and Breaking Governments: Cabinet and Legislatures in Parliamentary Democracies (Cambridge University Press, New York, 1996).

[43] Lewis, P., Political Parties in Post-Communist Eastern Europe (Routledge, London/New York, 2000).

[44] Linder, W., Schweizerische Demokratie: Institutionen, Prozesse, Perspektiven (Haupt, Bern, 2005).

[45] Linder, W., Swiss Democracy: Possible Solutions to Conflict in Multicultural Societies (Palgrave Macmillan, Houndmills, Basingstoke, 2010).

[46] Lutz, G., and Selb P., The National Elections in Switzerland, in Handbook of Swiss Politics, eds. Klöti, U., Knoepfel, P., Kriesi, H., Linder, W., Papadopoulos Y., and Sciarini P. (Neue Zürcher Zeitung Publishing, Zürich, 2007) pp. 405-33.

[47] Mitchell, P. Coalition Discipline, Enforcement Mechanisms, and Intraparty Politics, in Party Discipline and Parliamentary Government, eds. Bowler, S., Farrell D.M., and Katz R.S. (Ohio State University Press, Columbus, 1999) pp. 269-87.

[48] Nenadic, O., and Greenacre, M., Correspondence Analysis in R, with Two- and Threedimensional Graphics: The CA Package. Journal of Statistical Software 20 (2007) $1-13$.

[49] Oosterwaal, A., and Torenvlied R., Politics Divided from Society? Three Explanations for Trends in Societal and Political Polarisation in the Netherlands. West European Politics 33 (2010) 258-79.

[50] Ott, T., Kern, A., Steeb W.-H., and Stoop R., Sequential clustering: tracking down the most natural clusters. Journal of Statistical Mechanics: Theory and Experiments (2005) P11014.

[51] Ott, T., Kern, A., Schuffenhauer, A., Popov, M., Acklin, P., Jacoby E., and Stoop R., Sequential Superparamagnetic Clustering for Unbiased Classification of Highdimensional Chemical Data, Journal of Chemical Information and Computer Sciences 44 (2004) 1358-64.

[52] Owens, J.E., Explaining Party Cohesion and Discipline in Democratic Legislatures: Purposiveness and Contexts, Cohesion and Discipline in Legislatures, in Political Parties, Party Leadership, Parliamentary Committees and Governance, ed. Hazan 
R.Y. (Routledge, London/New York, 2006) pp. 12-40.

[53] Ozbudun, E., Party Cohesion in Western Democracies: A Causal Analysis (Sage Publications, Beverly Hills CA, 1970).

[54] Poole, K.T., Spatial Models of Parliamentary Voting (Cambridge University Press, Cambridge, 2005).

[55] Poole, K.T., and Rosenthal H., Congress: A Political-Economic History of Roll Call Voting (Oxford University Press, Oxford, 1997).

[56] Rice, S.A., The Behavior of Legislative Groups: A Method of Measurement, Political Science Quarterly 40 (1925) 60-72.

[57] Saalfeld, T., On Dogs and Whips: Recorded Votes, in Parliaments and Majority Rule in Western Europe, ed. Döring H. (Campus, Frankfurt a.M., 1995) pp. 528-65.

[58] Sartori, G., Parties and Party Systems: A Framework for Analysis (Cambridge University Press, Cambridge, 1976).

[59] Schindler, P., Datenhandbuch zur Geschichte des Deutschen Bundestages, 1949 bis 1990, Band II (Nomos, Baden-Baden, 1999).

[60] Schwarz, D., Zwischen Fraktionszwang und freiem Mandat. Eine Untersuchung des fraktionsabweichenden Stimmverhaltens im schweizerischen Nationalrat zwischen 1996 und 2005 (BoD, Norderstedt, 2009).

[61] Schwarz, D., Bächtiger A. and Lutz G., Switzerland: Agenda-Setting Power of Government in a Separation-of-Powers Framework, in The Role of Governments in Legislative Agenda Setting, eds. Rasch B.E., and Tsebelis G. (Routledge, Oxon, 2011) pp. 127-44.

[62] Sciarini, P., The Decision-Making Process, in Handbook of Swiss Politics Klöti, U., Knoepfel, P., Kriesi, H., Linder, W., Papadopoulos Y. and Sciarini P. (Neue Zürcher Zeitung Publishing, Zürich, 2007) pp. 465-99.

[63] Seitz, W., "Melonengrüne" und "Gurkengrüne": Die Geschichte der Grünen in der Schweiz, in Die Grünen in der Schweiz, eds. Baer M., and Seitz W. (Rüegger, Zürich/Chur, 2008) pp. 15-37.

[64] Taagepera, R., and Shugart M.S., Seats and Votes: The Effects and Determinants of Electoral Systems (Yale University Press, New Haven/London, 1989).

[65] Taagepera R., Making Social Sciences More Scientific. The Need for Predictive Models (Oxford University Press, Oxford, 2008).

[66] Thurman, J., and Gasser U., Three Case Studies from Switzerland: Smartvote, in Internet \& Democracy Case Study Series (Berkman Center Research Publication No. 2009-03.3, March 2009).

\section{Acknowledgments}

This work has been supported by the Cogito Foundation (Wollerau, Switzerland, grant number R-143/08).

\section{Appendix A. Superparamagnetic clustering}

The superparamagnetic clustering algorithm [4] SPC was inspired by a selforganization phenomenon in magnetic spin systems: in an inhomogeneous spin system, clusters of correlated spins can emerge, corresponding to groups of spins with strong couplings. Upon an increase in temperature, i.e. an increase in pressure on the system, these clusters decay into smaller units in a cascade of (pseudo-)phase transitions. For data clustering, we map a data set onto a spin system as follows: 
Each data item is represented by a Potts spin variable $s_{i}$ with possible values in $\{1, \ldots, q\}$. Each spin is coupled to its $k$ nearest neighbors, where, for given distances $d_{i j}=d_{j i}$ between spins, the couplings are determined according to:

$$
J_{i j}=J_{j i}=\frac{1}{k} \exp \left(\frac{-d_{i j}^{2}}{2 a^{2}}\right)
$$

$a$ is the average distance between neighbors. Each spin configuration $s$ is associated with the probability:

$$
p(s)=\frac{1}{Z(T)} \exp \left(\frac{-H(s)}{T}\right)
$$

with the Hamiltonian $H(s)=\sum J_{i j}\left(1-\delta_{s_{i} s_{j}}\right)$ and the normalization constant $Z(T)$. The parameter $T$ represents the system temperature. At a given $T$, clusters are detected by means of the pair correlation $G_{i j}=\sum p(s) \delta_{s_{i} s_{j}}$, approximately calculated by a Monte Carlo procedure. If $G_{i j}>\Theta$, then $s_{i}$ and $s_{j}$ belong to the same cluster. This formalism reveals several parameters that must be defined in a clustering procedure: the number of possible Potts spin values $q$, the number of nearest neighbors $k$, and the threshold $\Theta$. The choice of these parameters is too large to extend arbitrarily and does not influence the results substantially if a data set exhibits clear cluster structures [50]. Natural clusters, i.e., clusters with strong homogeneous couplings, become manifest in their stability over a substantial range of $T$. Hence, the $T$-stability provides a natural measure of cluster cohesion. This fact is also exploited by the sequential superparamagnetic clustering algorithm SSC (Ott et al. 2005). In this approach, the most stable cluster is extracted and it, as well as the residual set, is reclustered. The procedure is repeated, providing a natural binary tree with a cluster hierarchy. The couplings between spins and, hence, the clustering results critically depend on the distances $d_{i j}$ between the data points. The choice of the distance function is guided by the type of problem that one wants to solve and usually relies on the methodology of the scientific discipline in which one operates. It need not necessarily fulfill all axioms of a mathematical distance.

Using the framework of SPC and SSC for defining the coherence (with the dimensions 'cohesion' and 'factionalism') of belief systems requires in the first step a definition of the data points and their mutual distance. For $n$ data points, the application of the distance measure leads to an $n \times n$ distance matrix that serves as input for the clustering algorithm.

\section{Appendix B. Sensitivity Analysis}

The SPC and SCC clustering algorithms have been implemented by us in a platformindependent tool (freeware) ${ }^{\mathrm{s}}$. It goes along with a manual that describes the various

sThe tool is available at: http://stoop.ini.uzh.ch/research/clustering and http://www.ias.zhaw.ch/ de/science/ias/forschung/datenanalyse-statistik/sequential-clustering-software.html. 
parameters that can be defined when a specific clustering problem has to be solved. Besides the aforementioned parameters $k, q, \Theta$, there are a couple of tool-dependent parameters that allow for controlling the clustering resolution or clustering sensitivity in different ways. Generally, for high sensitivity, marginally stable (fluctuating) clusters can be detected and, as a consequence, the number of clusters increases. However, marginally stable clusters are not robust against small changes in the parameters. For data with no clear inherent structure, a sensitivity analysis, thus, must be performed to identify the robustness of the results for changing parameter conditions. In particular, one has to determine whether the system behaves (quasi)monotonously with respect to $C_{c}$ and (in particular) $C_{f}$. Due to the stochastic nature of the algorithm and the non-linear dependence of $C_{c}$ and $C_{f}$ on the calibration parameters, monotony is not guaranteed. For our data set, an extensive exploration of the parameter space revealed that $N T_{-}$steps is the main parameter that shows a quasi-monotonous behavior; i.e., there is an interval $[a, b]$ where $C_{f}$ is 0 for $N T_{\_}$steps $<a$ and $C_{f}$ becomes very large for $N T_{-}$steps $>b$ as the number of clusters in the binary tree 'explodes'. 